\title{
Acute Appendicitis Secondary to Enterobius Vermicularis Infestation: A Case Report
}

\author{
Abdellillah El Bakouri, Amal Hajri, Abdelhak Ettaoussi, Mounir Bouali, Fatimazahra Bensardi, \\ Khalid El Hattabi, and Abdelaziz Fadil
}

\begin{abstract}
The association of Enterobius vermicularis and appendicitis were recognized in the late XIXe century, when an incidence of $19 \%$ of appendicular infestation in children with appendicitis was reported. Other studies showed that the relationship between this parasitosis and appendicitis varied from 0.2 to 41.8 worldwid. In this paper we present an adult patient with acute appendicitis caused by Enterobius Vermicularis discovered in per-surgical procedure, and we're going to discuss on the bases of the literature the epidemiological, clinical, and therapeutic characteristics of the appendicular localization of oxyurosis.
\end{abstract}

Index Terms-Albendazole; appendicitis; Enterobius vermicularis;surgery.

\section{INTRODUCTION}

Enterobius vermicularis is an important and often unexpected finding in appendectomy specimen, most commonly seen in pediatric cases $[1,2]$. The role of this pinworm in the etiology of appendicitis is controversial. However the most widely reported phenomenon is one of appendicular colic due to the presence of a worm in the appendicular lumen [3, 4]. We report a case of acute appendicitis secondary to enterobius vermicularis infestation.

\section{Case report}

$\mathrm{He}$ is a 39 year old men; chronic smoking at 20 PA. Admitted to surgical emergency for right iliac fossa pain evolving 2 days before admission, associated with vomiting, all evolving in a context of feverish sensation.

Admission clinical examination found a patient who was hemodynamically and breathing conscious, stable. On the abdominal examination a sensitivity of the right iliac fossa and the rectal touch was without particularity. The NFS had objective a leukocytosis at 12000 element / mm3. An abdominal ultrasound revealed an aspect of uncomplicated acute appendicitis measuring $10 \mathrm{~mm}$ in diameter.

The procedure consisted of a retrograde appendectomy. With exploration an inflamed appendix retro-coecale with healthy base with presence of white worms on the trench of appendicular section (figure: 1) evoking a priori an appendix pinworm. The postoperative continuations was simple and the patient was declared outgoing on the first day postoperative under anti-helminthic oral therapy. The decline was 2 months.

Published on April 05, 2020.

Authors are with Ibn Rochd University Hospital, Casablanca, Morocco. (corresponding e-mail: amalhajri.282@gmail.com)

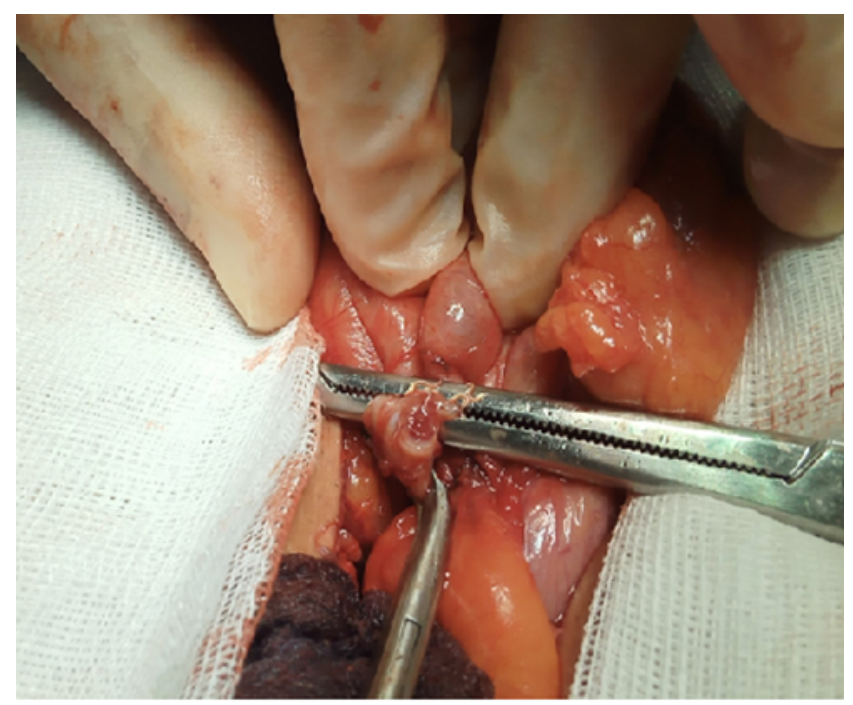

Fig 1: Intraoperative image showing the presence of white worms during the section of the appendix in favor of pinworm.

\section{DISCUSSION}

The reported incidence of $\mathrm{E}$. vermicularis appendicitis varies widely from 0.2 to $41.8 \%$, and young girls are mostly affected $[5,6]$. It remains unclear why females show a predominance in cases of appendicitis caused by $\mathrm{E}$. vermicularis, ranging from $74 \%$ to $76 \%[7,8]$.

The most common manifestation of $\mathrm{E}$. vermicularis is perianal pruritus that results from the migration of the female pinworm to lay its eggs in the perianal area [9]. However, it has also been noted to present as a mesenteric abscess, urinary tract infections, salpingitis, and appendicitis $[10,11]$.Before improved sanitary conditions, in 1899 Still reported that $19 \%$ of acute appendicitis occurred in conjunction with E. vermicularis infestation [12].

The relationship between E. vermicularis and pathogenesis of appendicitis had been studied for many years, the influence of the parasite to induce inflammation is still unclear. Although E. vermicularis (pinworm) may have a role in causing appendiceal disconfort or appendicular chronic inflammation due to obstruction, the majority of cases have no acute inflammation [13].

Enterobius infestation can cause diseases like acute appendicitis, chronic appendicitis and ruptured appendicitis is shared by others [14], and even more morbid complications like gangrenous appendicitis and perforation resulting in peritonitis [15]. None the less, there have been reports of completely asymptomatic patients [14]. 
The pathophysiology behind the association between E. vermicularis and clinically suspected appendicitis is similar to that associated with a faecolith or luminal lymphoid hyperplasia of the appendix [16] (figure 2). By obstructing the appendicular canal it produces colicky right iliac fossa (RIF) pain "appendicular colic" but unusually leads to appendicular inflammation $[16,17]$. It can therefore lead to a clinical scenario mimicking acute appendicitis but not necessarily cause it. This is important when deciding on the management approach to patients with RIF pain and suspected E. vermicularis as it is a treatable infection with common anti-helminthic oral therapy (recommendation for mebendazole) [18].

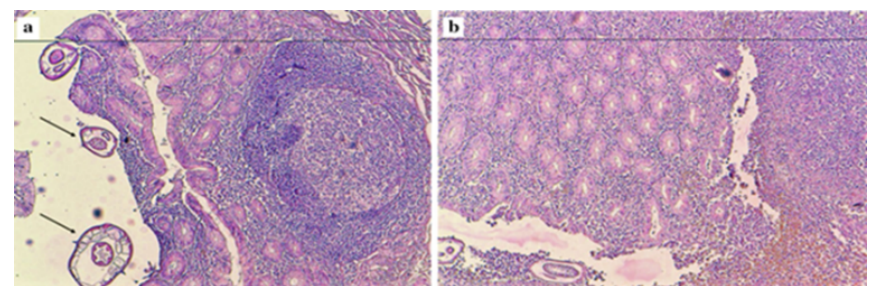

Fig. 2: a. The histological view showing the inflamed appendicular wall, with parasites in the lumen (black arrows). A hyperplastic lymphoid follicle is also seen in the mucosa and submucosa (hematoxylin-eosin-saffron $\times$ 100). b. Another section of the appendix showing histological signs of intense acute inflammation: epithelial ulceration and suppurative necrosis (hematoxylin-eosin-saffron $\times 100)$ [19].

We identified that one can clinically differentiate true appendicitis from appendiceal colic caused by E. vermicularis luminal obstruction in a pediatric patient who presents with RIF pain (namely Eosinophilia, normal WCC and normal Neutrophil count at presentation). In appendicular oxyurosis, several tissue changes can affect the appendix from lymphoid hyperplasia, granulomatous inflamation, phlegmonous inflamation, to perforation.

E. vermicularis are most often endoluminal $(90 \%$ of the cases), rarely intraparietal, because they can penetrate the mucous membrane only if it is damaged. The coexistance of other parasites with E. vermicularis is possible, but remains very rare.

When diagnosed intraoperatively, E. vermicularis should be treated based upon several principles. If any pinworms are appreciated, they should be controlled with thermal ablation or endoscopic suctioning [20]. A specimen bag should be implemented for removal of the appendix [20]. After removal of the appendix, the port sites, abdominal cavity, and pelvis should be meticulously examined for any spillage before closing [20]. These steps should be taken to protect against potential intraperitoneal contamination, which can be complicated by omentitis, pelvic inflammatory disease, and pelvic peritoneal granulomas [20]. Concurrent with surgical treatment, patients should be treated with a dose of mebenedazole, pyrantel pamoate, or albendazole at the time of diagnosis, and another dose 2 weeks after treatment [21]. Household contacts do not need to be treated for E. vermicularis unless more than one household member is affected or if the infection recurs [21].

\section{CONCLUSION}

Enterobius Vermicularis is a colonic parasitosis. The infection often remains asymptomatic and of incidental discovery that has histological examination of the operating room. Also, before digestive disorders suggestive of appendicitis, apart from surgical emergencies, a complete parasitic examination with repeated scotch tests is recommended. The positivity of these examinations would reduce the number of unnecessary appendectomies. In this case, a simple antiparasitic treatment is indicated.

\section{REFERENCES}

[1] M. Yilmaz, S. Akbulut, K. Kutluturk, N. Sahin, E. Arabaci, C. Ara, S. Yilmaz, Unusual histopathological findings in appendectomy specimens from patients with suspected acute appendicitis, World J. Gastroenterol. 19 (25) (2013) 4015e4022.

[2] S. Akbulut, M. Tas, N. Sogutcu, Z. Arikanoglu, M. Basbug, A. Ulku, H. Semur, Y. Yagmur, Unusual histopathological findings in appendectomy specimens: a retrospective analysis and literature review, World J. Gastroenterol. 17 (15) (2011) 1961e1970.

[3] M.A. Ramezani, M.R. Dehghani, Relationship between Enterobius vermicularis and the incidence of acute appendicitis, Southeast Asian J. Trop. Med. Public Health 38 (1) (2007) 20e23.

[4] D.F. da Silva, R.J. da Silva, M.G. da Silva, A.C. Sartorelli, M.A. Rodrigues, Parasitic infection of the appendix as a cause of acute appendicitis, Parasitol. Res. 102 (1) (2007) 99e102.

[5] Ariyarathenam AV, Nachimuthu S, Tang TY, Courtney ED, Harris SA, Harris AM. Enterobius vermicularis infestation of the appendix and management at the time of laparoscopic appendectomy: case series and literature review. Int J Surg. 2010; 8(6):466-9.

[6] Ahmed MU, Bilal M, Anis K, Khan AM, Fatima K, Ahmed I, et al. The frequency of Enterobius vermicularis infections in patients diagnosed with acute appendicitis in Pakistan. Glob J Health Sci. 2015; 7(5):196-201.

[7] Ahmed MU, Bilal M, Anis K, et al. The frequency of Enterobius vermicularis infections in patients diagnosed with acute appendicitis in Pakistan. Global J Health Sci 2015; 7:196-201.

[8] Lala S, Upadhyay V. Enterobius vermicularis and its role in paediatric appendicitis: Protection or predisposition? E. vermicularis in appendicitis. ANZ J Surg 2016; 86:717- 719.

[9] Dunphy L, Clark Z, Raja MH. Enterobius vermicularis (pinworm) infestation in a child presenting with symptoms of acute appendicitis: A wriggly tale! BMJ Case Rep 2017, pii.

[10] Sodergren MH, Jethwa P, Wilkinson S, Kerwat R. Presenting features of Enterobius vermicularis in the vermiform appendix. Scand J Gastroenterol 2009; 44:457-461.

[11] Akkapulu N, Abdullazade S. Is Enterobius vermicularis infestation associated with acute appendicitis? Eur J Trauma Emerg Surg 2016; 42:465-470.

[12] Arca M, Gates R, Groner J, Hammond S, Caniano D. Clinical manifestations of appendiceal pinworms in children: An institutional experience and a review of the literature. Pediatr Surg Int 2004;20:372-375.

[13] Gialamas E, Papavramidis T, Michalopoulos N, Karayannopoulou G, Cheva A, Vasilaki O, et al. Enterobius vermicularis: a rare cause of appendicitis. Türkiye parazitolojii dergisi. 2012; 36(1):37.

[14] Fallah E, Dehgani A. A Study On Entrobius Vermicularis Infection In A Appendices Removed By Surgery In Tabriz Hospitals.11th International Congress of Parasitology. 2008; 4(1):1-5.

[15] Madhukar KP, Verma R, Sayed Z, Vira L. Acute appendicitis secondary to enterobius vermicularis infestation in a young female: a case report. Journal of evolution of medical and dental sciences. 2014; 3(19):5219-23.

[16] O.G. Ajao, S. Jastaniah, T.S. Malatani, N. Morad, E.N. el Tayeb, et al., Enterobius vermicularis (pinworm) causing symptoms of appendicitis, Trop. Dr. 27 (1997) 182e183.

[17] M.J. Arca, R.I. Gates, J.I. Groner, S. Hammond, D.A. Caniano, Clinical manifestations of appendiceal pinworms in children: an institutional experience and a review of literature, Paediatr. Surg. Int. 20 (2004) 372e 375.

[18] A.C. Nackley, J.J. Nackley, T.R. Yeko, S. Gunasekaran, Appendiceal enterobius vermicularis infestation associated with right-sided chronic pelvic pain, J. Soc. Laparoendosc. Surg. 8 (2) (2004) $171 \mathrm{e} 173$.

[19] B.Efared, G. Atsame-Ebang, B. Marou Soumana, L. Tahiri, N. Hammas, H.El Fatemi , L. Chbani. Acute suppurstive apendicitis associated with Enterobius vermicularis: an incidental finding or a causative agent? A case report. BMC Res Notes (2017)10:494. 
[20] Kaczynski J, Hilton J. An "appendiceal colic" caused by the Enterobius vermicularis. Case Rep 2014; 2013-2014.

[21] Center for Disease Control and Prevention. Parasites Enterobiasis (also known as pinworm infection) Treatment. 2016. https://www.cdc.gov/parasites/pinworm/ treatment.html (last accessed July 1, 2018).

\section{Conflicts of interest: None to declare.}

Author contributions: All authors have contributed to the conduct of this work. All authors also declare that they have read and approved the final version of the manuscript.

\section{Abdelillah EL BAKOURI}

e-mail: A.elbakouri@gmail.com

Hassan 2 University of Casablanca, Morocco

Institution: Department of Visceral Surgical Emergency (P35),

Ibn Rochd University Hospital, Casablanca, Morocco.

\section{Amal HAJRI}

Casablanca, Morocco 20400

Telephone: 00212613299259

e-mail: amalhajri.282@gmaill.com

Institution: Department of General Surgery III, Ibn Rochd University

Hospital, Casablanca, Morocco.

\section{Abdelhak ETTAOUSSI}

e-mail: ettaoussi.abdelhak@gmail.com

Hassan 2 University of Casablanca, Morocco

Institution: Department of Visceral Surgical Emergency (P35),

Ibn Rochd University Hospital, Casablanca, Morocco.

\section{Mounir BOUALI}

e-mail: boualimounir@hotmail.com

Hassan 2 University of Casablanca, Morocco

Institution: Department of Visceral Surgical Emergency (P35),

Ibn Rochd University Hospital, Casablanca, Morocco.

\section{Fatimazahra BENSARDI}

e-mail: fatisardi@yahoo.fr

Hassan 2 University of Casablanca, Morocco

Institution: Department of Visceral Surgical Emergency (P35),

Ibn Rochd University Hospital, Casablanca, Morocco.

\section{Khalid EL HATTABI}

e-mail: elhattabi.khalid@yahoo.fr

Hassan 2 University of Casablanca, Morocco

Institution: Department of Visceral Surgical Emergency (P35),

Ibn Rochd University Hospital, Casablanca, Morocco.

\section{Abdelaziz FADIL}

e-mail: fadilaziz@yahoo.fr

Hassan 2 University of Casablanca, Morocco

Institution: Department of Visceral Surgical Emergency (P35),

Ibn Rochd University Hospital, Casablanca, Morocco. 